\title{
$\mathrm{DME}$ 분리공정의 열역학적 해석에 대한 연구
}

\author{
조정호 ${ }^{1}$, 김영우 $^{2^{*}}$ \\ ${ }^{1}$ 공주대학교 화학공학부, ${ }^{2}$ 호서대학교 자동차공학과
}

\section{A Study on the Thermodynamic Analysis for the DME Separation Process}

\author{
Jungho $\mathrm{Cho}^{1}$ and Young-Woo $\mathrm{Kim}^{2 *}$ \\ ${ }^{1}$ Department of Chemical Engineering, Kongju National University, \\ ${ }^{2}$ Department of Automotive Engineering, Hoseo University
}

\begin{abstract}
요 약 본 연구에서는 디젤대체 연료와 LPG 혼합용 및 도시 가스의 발열량을 높이기 위한 첨가제로 사용할 수 있 는 DME 분리공정에 대한 올바른 열역학 모델식의 선정에 대한 해석을 시도하였다. 물과 메탄올 용매 사이의 액상에 서의 비이상성을 해석하기 위해서 NRTL 액체 활동도계수 모델식을 사용하였으며, 기상에서 이상기체의 비이상성을 해석하기 위해서 Peng-Robinson 상태방정식을 사용하였다. 한편, Methanol absorber에서 메탄올 수용액 중의 $\mathrm{H}_{2}, \mathrm{CO}$, $\mathrm{CO}_{2}, \mathrm{H}_{2}, \mathrm{CH}_{4}$ 과 $\mathrm{N}_{2}$ 등과 같은 비응축성 기체의 용해도를 추산하기 위해서 온도와 압력의 함수로 나타낸 Henry parameter를 사용하였다. 사례 연구를 통해서 원료에 대한 용매의 몰 유량비가 3.40 일 때 최적이 됨을 알 수 있었다.
\end{abstract}

\begin{abstract}
Through this study, we have attempted the thermodynamic analysis on the dimethyl ether (DME) separation process, which can be used for diesel alternative fuel, additive to LPG and natural gas. And we also have completed the simulation of DME separation process using PRO/II with PROVISION. As an appropriate thermodynamic models, we selected NRTL liquid activity coefficient model to describe the non-ideality between methanol and water. To estimate the vapor phase non-idealities, we have chosen the Peng-Robinson equation of state model. And we also use the Henry's law option to predict the solubilities of non-condensible gases like $\mathrm{CO}, \mathrm{CO}_{2}, \mathrm{H}_{2}, \mathrm{CH}_{4}$ and $\mathrm{N}_{2}$ in methanol solvent. Case study showed that optimal solvent to feed molar ratio was 3.40
\end{abstract}

Key Words : Dimethyl ether, Two-model approach, Thermodynamic model, Separation process

\section{1. 서론}

Dimethyl Ether (DME)는 디젤 대체연료로 각광받고 있으며 특히 합성공정에서 온실가스인 이산화탄소를 원 료로 사용하기 때문에 환경적인 측면에서도 우수한 연료 로 평가받고 있다. $\mathrm{DME}$ 의 합성은 천연가스로부터 얻어 질 수 있는데 아래의 식 (1)에서 식 (5) 사이에 DME 합성 반응에 대해서 나타내었다.

$$
3 \mathrm{CH}_{4}+3 \mathrm{CO}_{2} \rightarrow 6 \mathrm{CO}+6 \mathrm{H}_{2}
$$

$$
\begin{aligned}
& 2 \mathrm{CO}+4 \mathrm{H}_{2} \rightarrow 2 \mathrm{CH}_{3} \mathrm{OH} \\
& 2 \mathrm{CH}_{3} \mathrm{OH} \rightarrow \mathrm{CH}_{3} \mathrm{OCH}_{3}+\mathrm{H}_{2} \mathrm{O} \\
& \mathrm{CO}+\mathrm{H}_{2} \mathrm{O} \rightarrow \mathrm{CO}_{2}+\mathrm{H}_{2} \\
& 3 \mathrm{CO}+3 \mathrm{H}_{2} \rightarrow \mathrm{CH}_{3} \mathrm{OCH}_{3}+\mathrm{CO}_{2}
\end{aligned}
$$

위의 식 (1)에서 식 (4)는 DME의 합성경로를 나타낸 것이다. 식 (1)에서는 메탄과 이산화탄소가 반응하여 합 성가스를 생성하고, 식 (2)에서는 합성가스로부터 메탄올 을 합성하는 반응을 나타내었다. 한편 식 (3)에서는 메탄

본 논문은 지식경제부 중대형사업의 “청정기술사업”과 한국가스공사의 연구과제로 수행되었음.

*교신저자: 김영우(ywkim@hoseo.edu)

접수일 09년 10월 05일

수정일 (1차 10년 01월 17일, 2차 10년 02월 23일)

게재확정일 10 년 02 월 24 일 
올의 탈수반응에 DME가 생성되는 반응을 나타내었으며, 식 (4)는 일산화탄소의 Shift 반응을 나타내었다. 한편 식 (5)는 전체 반응을 나타내었다. DME는 상압 조건하에서 는 $-25^{\circ} \mathrm{C}$ 이하에서 $25^{\circ} \mathrm{C}$ 온도 조건하에서는 $4.82 \mathrm{Kg} / \mathrm{cm}^{2} \mathrm{G}$ 이상의 압력 조건에서 액화가 가능하기 때문에 $\mathrm{LNG}$ 에 비해서 수송하기 위한 에너지 소모가 적게 소요되는 장 점이 있다.

본 연구에서는 데모 플랜트 수준으로 일산 10 톤 급으 로 순도 $99.9 \%$ 를 갖는 $\mathrm{DME}$ 를 분리해 내는 공정을 상용 성 화학공정 모사기인 Invensys사의 $\mathrm{PRO} / \mathrm{II}$ with PROVISION을 사용하여 모사하였다[1]. 열역학 모델식 으로는 액상에서의 비이상성을 설명하기 위해서 Renon 과 Prausnitz 등이 제안한 NRTL 액체 활동도계수 모델식 을 사용하였으며[2], 흡수탑의 경우 운전압력이 60기압 정도이므로 기상에서의 비이상성을 설명하기 위해서 Peng-Robinson 상태방정식을 적용하였다[3]. 한편 $\mathrm{CO}$, $\mathrm{CO}_{2}, \mathrm{H}_{2}$ 및 $\mathrm{CH}_{4}$ 와 같은 기체 성분의 메탄올 용매에서의 용해도를 추산하기 위해서 Henry의 법칙을 추가적으로 이용하였다[4]. 통상적인 $\mathrm{DME}$ 분리공정은 아래의 그림 1과 그림 2에 나타낸 바와 같이 총 4기의 Column들도 구 성된다. Tri-reformer에서 나온 기상류 중에 포함되어 있 는 이산화탄소를 흡수하기 위해서 용매로 메탄올을 사용 하며 Stripper의 상부로 이산화탄소를 기상으로 얻어낸다. 한편 $\mathrm{DME}$ 합성 반응공정에서 나온 $\mathrm{DME}$ 를 포함하는 다 성분계인 스트림은 첫 번째 Column에서 이산화탄소를 제거하고 그 다음 Column에서 탑상제품으로 DME를 얻 어내고 탑저로 메탄올과 물을 얻어내는 공정으로 구성되 어 있다.

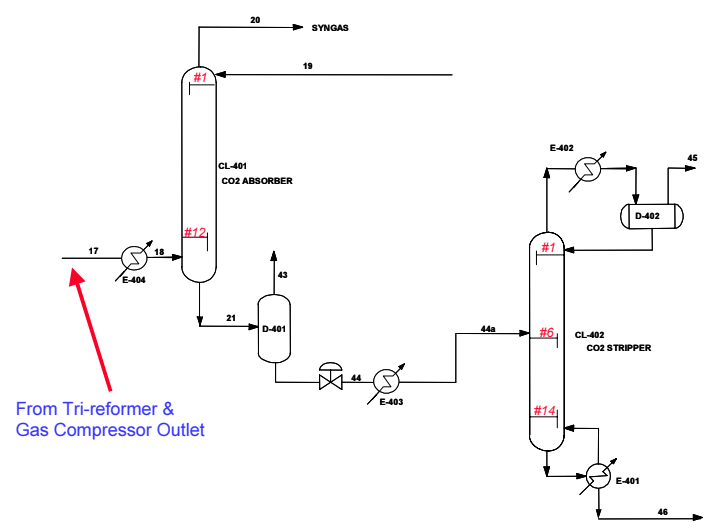

[그림 1] $\mathrm{CO}_{2}$ 흡수탑과 $\mathrm{CO}_{2}$ Stripper에 대한 개요도

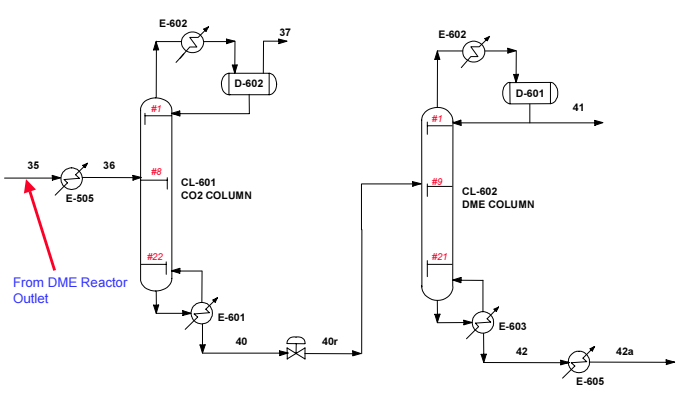

[그림 2] $\mathrm{CO}_{2}$ Column과 DME Column에 대한 개요도

\section{2. $\mathrm{DME}$ 분리공정에 대한 열역학 모델식}

기액 상평형을 추산할 수 있는 방법은 두 가지가 가능 하다. 첫 번째 방법으로는 혼합물 중의 성분 ' $\mathrm{i}$ '의 기상과 액상에서의 퓨개시티를 모두 상태방정식을 이용하는 것 이다. 이를 One model approach라고 부르며 원리상 아래 의 식 (6)과 같이 쓸 수 있다.

$$
\widehat{\phi_{i}^{v}}\left(T, P, y_{i}\right) y_{i}=\widehat{\phi_{i}^{l}}\left(T, P, x_{i}\right) x_{i}
$$

한편, 액상의 비이상성에 대해서는 액체 활동도계수 모델식을 사용하고 기상의 비이상성에 대해서는 상태방 정식 모델식을 각각 적용하는 것을 Two model approach 라고 한다. 이는 아래의 식 (7)에 나타내었으며 기체의 용 매에 대한 용해도를 추산하기 위해서 식 (7)의 증기압 대 신에 헨리상수를 적용하는데 이는 식 (8)에 나타내었다.

$$
\begin{aligned}
& \widehat{\phi_{i}^{v}}\left(T, P, y_{i}\right) y_{i} P=\gamma_{i}\left(T, P, x_{i}\right) x_{i} P_{i}^{v a p}(T) \\
& y_{i} P=\gamma_{i} H(T, P) x_{i}
\end{aligned}
$$

액상의 활동도계수를 계산하기 위해서 NRTL 액체 활 동도계수 모델식을 사용하였는데 이는 아래의 식 (9)에서 식 (11) 사이에 나타내었다. 액상의 비이상성을 설명하기 위해서는 상태방정식 모델식 보다는 액체 활동도계수 모 델식이 더 적합한 것으로 알려져 있다. 한편 여러 가지 액체활동도계수 모델 중에서 NRTL 모델식을 선정한 이 유는 물과 알콜 시스템과 같이 액상에서의 비이상성이 큰 혼합물의 상거동을 잘 추산하기 때문이다.

$$
\ln \gamma_{i}=\frac{\sum_{j} \tau_{j i} G_{j i} x_{j}}{\sum_{k} G_{k i} x_{k}}+\sum_{j} \frac{x_{j} G_{i j}}{\sum_{k} G_{k j} x_{k}}\left[\tau_{i j}-\frac{\sum_{l} x_{l} \tau_{l j} G_{l j}}{\sum_{k} G_{k j} x_{k}}\right] \text { (9) }
$$




$$
\begin{aligned}
& \tau_{i j}=a_{i j}+\frac{b_{i j}}{T} \\
& G_{i j}=\exp \left(-\alpha_{i j} \tau_{i j}\right)
\end{aligned}
$$

아래의 표 1 에는 물과 메탄올 사이의 NRTL 모델식에 대한 이성분계 상호작용 매개변수를 나타내었다. NRTL 파라메터는 각각의 이성분계에 대해서 $a_{i j}, a_{j i}, b_{i j}, b_{j i}$ 및 $\alpha_{i j}$ 를 갖는다. 표 1 의 NRTL 파라메터는 메탄올과 물 사 이의 온도-조성에 대한 기-액 상평형 실험 데이터를 회귀 분석을 통해서 결정하였으며, 회귀분석에 사용한 목적함 수는 식 (12)와 같으며, 회귀분석 알고리즘은 Nelder와 Mead가 제안한 Pattern search 알고리즘을 사용하였다[5].

[표 1] 물과 메탄올 사이의 NRTL 파라메터[9]

\begin{tabular}{ccccc}
\hline \multirow{2}{*}{ 성분 $\mathrm{i}$} & \multirow{2}{*}{ 성분 $\mathrm{j}$} & $\begin{array}{c}a_{i j} \\
a_{j i}\end{array}$ & $b_{i j}$ & $\alpha_{i j}$ \\
\hline \multirow{2}{*}{ 메탄올 } & \multirow{2}{*}{ 물 } & 0.73611 & -360.69 & \multirow{2}{*}{0.2442} \\
\hline
\end{tabular}

$$
F=\sum_{j=1}^{N}\left(\frac{T_{j}^{\mathrm{exp}}-T_{j}^{c a l}}{T_{j}^{c a l}}\right)^{2}-\sum_{j=1}^{N}\left(\frac{y_{j}^{\mathrm{exp}}-y_{j}^{c a l}}{y_{j}^{c a l}}\right)^{2}
$$

상기 식 (12)는 일정 압력하에서 이성분계에 대하여 온도와 조성에 대한 실험 데이터가 주어져 있을 때 이를 잘 추산하기 위하여 사용한 목적함수의 형태이다.

기상의 퓨개시티계수를 계산하기 위해서 Peng-Robinson 상태방정식을 사용하였는데 이는 다음의 식 (13)과 같이 표현된다. 많은 상태방정식 중에서 Peng-Robinson 상태방정식을 사용한 이유는 3차 방정식 이기 때문에 해석적인 근이 존재하며 빠른 계산 결과를 얻을 수 있으며, 언제나 수렴하는 결과를 얻을 수 있다는 장점이 있다.

$$
P=\frac{R T}{v-b}-\frac{a \alpha}{v(v+b)-b(v-b)}
$$

위의 식 (13)에서 $a$ 와 $b$ 는 각각 energy parameter와 size parameter로써 각각 임계온도와 임계압력의 함수로 써 식 (14)와 식 (15)와 같이 나타낼 수 있다. 또한 다른 종류의 3차형 상태방정식 중에서 가장 정확성이 뛰어난 것으로 알려져 있다.

$$
a=0.45723 \frac{R^{2} T_{c}^{2}}{P_{c}}
$$

$$
b=0.07780 \frac{R T_{c}}{P_{c}}
$$

한편 식 (13)에서 $\alpha$ 는 alpha function으로써 순수성분 의 온도에 따른 증기압을 잘 추산하기 위해서 도입한 각 성분의 환산온도와 편심인자의 함수인데 원식은 다음의 식 (16)과 식 (17)과 같이 표현된다.

$$
\begin{aligned}
& \alpha=\left[1+m\left(1-\sqrt{T_{r}}\right)\right]^{2} \\
& m=0.37464+1.54336 \omega-0.26992 \omega^{2}
\end{aligned}
$$

그런데 위의 식 (17)의 우변의 편심인자 앞의 계수들 은 제한된 종류의 탄화수소와 이산화탄소, 질소 등과 같 은 성분들의 온도에 따른 증기압 실험 데이터를 모두 모 아서 회귀분석을 통해서 결정한 것이다. 따라서 탄화수소 성분 이외의 물, 메탄올이나 DME 성분들의 온도에 따른 증기압 추산에 적용하기에는 한계가 있다. 이러한 단점을 보완하기 위해서 이제는 각각의 순수성분의 온도에 따른 증기압 실험 데이터를 성분 각각에 대해서 회귀분석을 통해서 결정하는데 새로운 alpha function을 사용하였다 [6]. 이는 식 (18)에 나타내었다. 한편 표 2에는 PRO/II with PROVISION에 내장되어 있는 DME 분리공정에 존 재하는 순수성분에 대해서 alpha function 앞의 계수인 $C_{1}, C_{2}$ 와 $C_{3}$ 를 나타내었다.

$$
\alpha=T_{r}^{C_{3}\left(C_{2}-1\right)} \exp \left[C_{1}\left(1-T_{r}^{C_{2} C_{3}}\right)\right]
$$

[표 2] 순수 성분에 대한 Alpha function에 대한 계수 들[9]

\begin{tabular}{lccc}
\hline \multicolumn{1}{c}{ Component } & $C_{1}$ & $C_{2}$ & $C_{3}$ \\
\hline 1. $\mathrm{CO}$ & 0.0746 & 0.8722 & 2.2635 \\
2. $\mathrm{H}_{2} \mathrm{O}$ & 0.3846 & 0.8700 & 1.9637 \\
3. $\mathrm{CO}_{2}$ & 0.2047 & 0.8197 & 0.0000 \\
4. $\mathrm{H}_{2}$ & 0.9267 & 4.2324 & 0.1200 \\
5. $\mathrm{CH}_{3} \mathrm{OH}$ & 0.7515 & 0.9320 & 1.6042 \\
6. $\mathrm{CH}_{3} \mathrm{OCH}$ & 0.1140 & 0.8996 & 3.7232 \\
7. $\mathrm{CH}_{4}$ & 0.1195 & 0.9040 & 0.0000 \\
8. $\mathrm{N}_{2}$ & 0.5764 & 0.9093 & 0.6765 \\
\hline
\end{tabular}

또한 Peng-Robinson 상태방정식을 혼합물에 적용하기 위해서 energy parameter와 size parameter에 대해서 혼합 규칙을 적용할 수 있는데 이는 아래의 식 (19)와 식 (20) 과 같이 표현할 수 있다. 


$$
\begin{aligned}
a_{\text {mix }} & =\sum_{i} \sum_{j} x_{i} x_{j} a_{i j} \\
b_{\text {mix }} & =\sum_{i} x_{i} b_{i}
\end{aligned}
$$

위의 식 (19)에서 성분 'i'와 성분 'j' 사이의 이성분계 에 대한 energy parameter인 $a_{i j}$ 에 대해서는 van der Waals 혼합규칙을 사용하였는데 이는 식 (21)과 같이 쓸 수 있다.

$$
a_{i j}=\sqrt{a_{i} a_{j}}\left(1-k_{i j}\right)
$$

위의 식 (21)에서 $k_{i j}$ 는 이성분계 상호작용 매개변수 로써 이는 각각의 이성분계 사이의 기액 상평형 실험 데 이터를 잘 추산하도록 회귀분석을 통해서 결정한다. 한편 $\mathrm{DME}$ 분리공정에 참여하는 각각의 이성분계에 대한 이 성분계 상호작용 매개변수는 표 3에 나타내었다. 한편 아 래의 성분 'i'와 성분 'j'에서 1 에서 8 사이의 숫자는 각각 표 2에서 제시한 성분의 번호와 일치한다. 한편, 비응축 성 기체의 용매에 대한 용해도를 추산하기 위해서 Henry 의 법칙을 사용하였는데 이는 다음의 식 (22)와 같이 표 현할 수 있다.

$$
\ln H=C_{1}+\frac{C_{2}}{T}+C_{3} \ln T+C_{4} P
$$

[표 3] 각각의 이성분계 사이의 이성분계 상호작용 매 개변수 값 $(\mathrm{PRO} / \mathrm{II})$ [9]

\begin{tabular}{ccc|ccc}
\hline 성분 $\mathrm{i}$ & 성분 $\mathrm{j}$ & $k_{i j}$ & 성분 $\mathrm{i}$ & 성분 $\mathrm{j}$ & $k_{i j}$ \\
\hline 1 & 2 & 0.200 & 2 & 8 & 0.508 \\
1 & 3 & -0.030 & 3 & 4 & -0.162 \\
1 & 4 & 0.090 & 3 & 5 & 0.014 \\
1 & 7 & 0.030 & 3 & 7 & 0.092 \\
1 & 8 & 0.012 & 3 & 8 & -0.017 \\
2 & 3 & 0.210 & 4 & 7 & 0.016 \\
2 & 4 & 0.563 & 4 & 8 & -0.030 \\
2 & 5 & -0.079 & 5 & 8 & -0.270 \\
2 & 7 & 0.500 & 7 & 8 & 0.035 \\
\hline
\end{tabular}

식 (22)에 의하면 기체의 액체에 대한 용해도는 온도 에 비례하고 압력에는 반비례하는 것을 알 수 있다. 용질 가스와 용매인 메탄올과 물에 대한 온도와 압력의 함수 로 주어지는 Henry 상수는 PRO/II with PROVISION에 내장되어 있는 것을 사용하였으며 표 4에 나타내었다. 단, 위의 식 (22)에서 온도 단위는 $\mathrm{K}$ 이며, 압력단위는 $\mathrm{kPa}$ 이다. 또한 본 연구에서 적용한 Two model approach
와의 비교연구를 위해서 HYSYS 공정모사기[7]에 내장 되어 있는 모델식인 PRSV 모델[8]을 사용한 분리공정 모 사 결과와 비교하였는데 PRSV 모델식의 Functional form 은 식 (13)과 동일하며, 혼합규칙은 아래의 식 (23)과 같 은 형태로 표현된다.

[표 4] 용질기체와 용매 사이의 Henry 상수[9]

\begin{tabular}{cccccc}
\hline 성분 $\mathrm{i}$ & 성분 $\mathrm{j}$ & $C_{1}$ & $C_{2}$ & $C_{3}$ & $C_{4}$ \\
\hline 1 & 2 & 166.7 & $-7,847.2$ & -21.9 & $9.87 \mathrm{E}-7$ \\
1 & 5 & 8.82 & $1,144.4$ & 0.0 & 0.0 \\
1 & 6 & 154.9 & $-8,498.7$ & -20.1 & $7.30 \mathrm{E}-6$ \\
3 & 2 & 217.0 & $-10,620.0$ & -30.1 & 0.0 \\
3 & 6 & 134.6 & $-6,535.4$ & -18.3 & 0.0 \\
4 & 2 & 116.4 & $-4,881.3$ & -14.8 & $3.55 \mathrm{E}-6$ \\
4 & 5 & 15.6 & 271.3 & -0.5 & 0.0 \\
4 & 6 & 223.4 & $-8,787.1$ & -31.9 & 0.0 \\
7 & 2 & 169.9 & $-8,132.2$ & -22.4 & $1.44 \mathrm{E}-6$ \\
7 & 5 & -63.2 & $2,617.0$ & 11.5 & 0.0 \\
8 & 2 & 158.3 & $-7,260.1$ & -20.7 & $1.44 \mathrm{E}-6$ \\
8 & 5 & 27.8 & -598.9 & -2.3 & 0.0 \\
\hline
\end{tabular}

$$
a_{i j}=\sqrt{a_{i} a_{j}}\left[1-\frac{k_{i j} k_{j i}}{x_{i} k_{i j}+x_{j} k_{j i}}\right]
$$

위의 식 (23)의 혼합규칙에 의하면 각각의 이성분계 쌍에 대해서 2개의 상호작용 매개변수를 사용하도록 되 어 있는데, HYSYS에 내장되어 있는 매개변수를 자세히 살펴보면 매개변수 $k_{i j}$ 와 매개변수 $k_{j i}$ 를 같은 값을 사 용하였다. 이 경우에는 van der Waals 혼합규칙과 같아진 다. 한편 HYSYS에 내장되어 있는 PRSV 혼합규칙에 대 한 이성분계 상호작용 매개변수를 표 5에 나타내었다.

[표 5] 각각의 이성분계 사이의 이성분계 상호작용 매 개변수 값 (HYSYS) [7]

\begin{tabular}{ccc|ccc}
\hline 성분 $\mathrm{i}$ & 성분 $\mathrm{j}$ & $k_{i j}$ & 성분 $\mathrm{i}$ & 성분 $\mathrm{j}$ & $k_{i j}$ \\
\hline 1 & 2 & -0.3896 & 3 & 5 & 0.04 \\
1 & 3 & -0.0314 & 3 & 6 & $\mathrm{X}$ \\
1 & 4 & 0.0253 & 3 & 7 & 0.1 \\
1 & 5 & $\mathrm{X}$ & 3 & 8 & -0.02 \\
1 & 6 & $\mathrm{X}$ & 4 & 5 & $\mathrm{X}$ \\
1 & 7 & 0.021 & 4 & 6 & $\mathrm{X}$ \\
1 & 8 & 0.0115 & 4 & 7 & 0.2023 \\
2 & 3 & 0.0445 & 4 & 8 & -0.036 \\
2 & 4 & 0.2998 & 5 & 6 & $\mathrm{X}$ \\
2 & 5 & -0.18 & 5 & 7 & -0.035 \\
2 & 6 & $\mathrm{X}$ & 5 & 8 & -0.2141 \\
2 & 7 & 0.48 & 6 & 7 & $\mathrm{X}$ \\
2 & 8 & -0.3156 & 6 & 8 & $\mathrm{X}$ \\
3 & 4 & 0.1202 & 7 & 8 & 0.036 \\
\hline
\end{tabular}


위의 표 5 에 의하면 8 개 성분에 대해서 각각의 이성분 계의 기-액 상평형을 완벽하게 모사하기 위한 이성분계 상호작용 매개변수의 숫자는 총 $\frac{8 \times 7}{2 !}=28$ 개다. 그런데 HYSYS에 내장되어 있는 이성분계 상호작용 매개변수는 19 개 이성분계 쌍에 대해서만 내장되어 있다. 더욱이 PRSV 모델식은 각각의 이성분계에 대해서 2개의 서로 다른 매개변수를 사용하여야 함에도 불구하고 1 개의 상 호작용 매개변수만을 사용하고 있다. 이것은 식 (23)에 나타낸 혼합규칙을 사용한 것이 아니라 식 (21)의 van der Waals 혼합규칙을 사용한 것이 된다. 따라서 PRSV 모델식은 $\mathrm{DME}$ 분리공정의 모사에는 적합한 열역학 모 델식이 아님을 알 수 있다.

\section{3. $\mathrm{DME}$ 분리공정의 전산모사}

\section{$3.1 \mathrm{CO}_{2}$ 흡수탑과 $\mathrm{CO}_{2}$ Stripper에 대한 전산 모사}

그림 1에 나타낸 $\mathrm{CO}_{2}$ 흡수탑과 $\mathrm{CO}_{2}$ Stripper 에 대한 전산모사를 Invensys사의 PRO/II with PROVISION을 이 용하여 수행하였으며, 표 6에는 원료와 용매에 대한 조건 을 나타내었다. 본 공정의 목적은 원료 가스 중에서 $\mathrm{CO}_{2}$ 성분을 메탄올 용매를 이용하여 대부분을 흡수한 다음에 $\mathrm{CO}_{2}$ Stripper 상부 증기류로 제거하는 것이다. 한편 표 7에는 $\mathrm{CO}_{2}$ 흡수탑과 $\mathrm{CO}_{2}$ Stripper에 대한 설계 조건 및 전사모사 결과를 나타내었다. 표 6에 의하면 용매로써 메 탄올의 농도는 $95.0 \mathrm{~mole} \%$ 로 하였는데 이는 메탄올의 순 도를 고순도로 하게 되면 $\mathrm{CO}_{2}$ Stripper 이후에 메탄올 분 리탑이 하나 더 추가적으로 필요하기 때문이다. 표 7에 의하면 $\mathrm{CO}_{2}$ 흡수탑의 운전압력이 $6,000 \mathrm{kPa}$ 에서 원료에 대한 용매의 몰 비를 3.40 으로 하였을 때, $\mathrm{CO}_{2}$ 흡수율이 $97.28 \%$ 이었으며, $\mathrm{CO}_{2}$ Stripper에서는 운전압력을 3,000 $\mathrm{kPa}$ 로 하였을 때, $\mathrm{CO}_{2}$ 의 원료에 대한 제거율은 $96.28 \%$ 로 써 대부분의 $\mathrm{CO}_{2}$ 가 제거됨을 알 수 있다. 그림 3 에 의하 면 $\mathrm{CO}_{2}$ 흡수탑에서 용매의 주입 유량에 따른 $\mathrm{CO}_{2}$ 의 흡 수율을 나타내었다. 용매의 유량이 $250 \mathrm{Kmole} / \mathrm{hr}$ 에서 $320 \mathrm{Kmole} / \mathrm{Hr}$ 의 구간에서는 $\mathrm{CO}_{2}$ 흡수율에 대한 증가율 이 거의 일정하게 유지되다가 $97.5 \%$ 의 $\mathrm{CO}_{2}$ 흡수율에서 거의 일정한 값으로 유지되는 것을 알 수 있다. 따라서 본 연구에서는 원료에 대한 용매의 유량에 대한 몰 비를 3.40 (용매 주입유량은 $329.8 \mathrm{Kmole} / \mathrm{hr}$ )으로 고정시켰다.

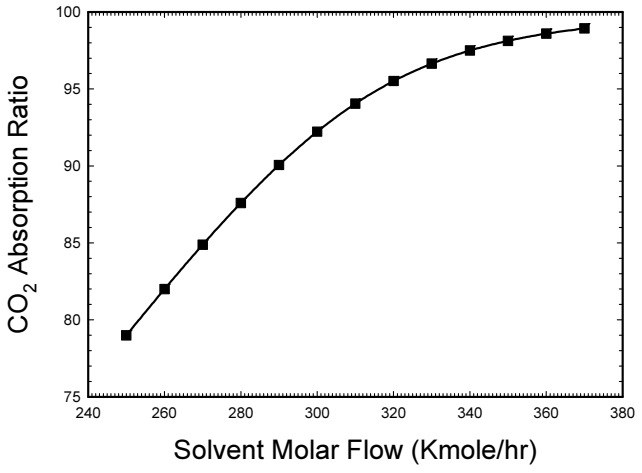

[그림 3] 용매 유량에 대한 이산화탄소 흡수율

[표 6] 원료와 용매의 입력 조건

\begin{tabular}{lrr}
\hline \multicolumn{1}{c}{ 성분 } & \multicolumn{1}{c}{ 원료 } & \multicolumn{1}{c}{ 용매 } \\
\hline 1. $\mathrm{CO}$ & 33.6229 & 0.0000 \\
2. $\mathrm{H}_{2} \mathrm{O}$ & 0.1843 & 16.4884 \\
3. $\mathrm{CO}_{2}$ & 26.5724 & 0.0000 \\
4. $\mathrm{H}_{2}$ & 36.2995 & 0.0000 \\
5. $\mathrm{CH}_{3} \mathrm{OH}$ & 0.0000 & 313.2788 \\
6. $\mathrm{CH}_{3} \mathrm{OCH} \mathrm{CH}_{3}$ & 0.0000 & 0.0000 \\
7. $\mathrm{CH}_{4}$ & 0.1843 & 0.0000 \\
8. $\mathrm{N}_{2}$ & 0.1067 & 0.0000 \\
Flow $(\mathrm{kmol} / \mathrm{hr})$ & 96.9700 & 329.7672 \\
Temperature $\left({ }^{\circ} \mathrm{C}\right)$ & 42.70 & 32.00 \\
Pressure $(\mathrm{kPa})$ & 6,000 & 6,000 \\
\hline
\end{tabular}

[표 7] $\mathrm{CO}_{2}$ 흡수탑과 $\mathrm{CO}_{2}$ Stripper에 대한 설계 조건 및 전산모사 결과

\begin{tabular}{cccc}
\hline 항목 & 단위 & $\begin{array}{c}\mathrm{CO}_{2} \\
\text { 흡수탑 }\end{array}$ & $\begin{array}{c}\mathrm{CO}_{2} \\
\text { Stripper }\end{array}$ \\
\hline 이론단수 & 단 & 10 & 12 \\
운전압력 & $\mathrm{kPa}$ & 6,000 & 3,200 \\
$\mathrm{~S} / \mathrm{F}$ mole Ratio & - & 3.40 & - \\
메탄올 농도 & $\mathrm{mol} \%$ & 95.0 & 94.87 \\
용매 유량 & $\mathrm{Kmol} / \mathrm{h}$ & 329.8 & - \\
$\mathrm{CO}_{2}$ 흡수율 & $\%$ & 97.28 & - \\
탑저 CO 유량 & $\mathrm{Kmol} / \mathrm{h}$ & 2.3649 & - \\
응축기 Duty & $10^{6} \mathrm{Kcal} / \mathrm{h}$ & - & -0.5393 \\
재배기 Duty & $10^{6} \mathrm{Kcal} / \mathrm{h}$ & - & 1.3098 \\
$\mathrm{CO}_{2}$ 제거율 & $\%$ & - & 96.28 \\
\hline
\end{tabular}

\section{$3.2 \mathrm{CO}_{2}$ Column과 DME Column에 대한 전 산모사}

그림 2에 나타낸 $\mathrm{CO}_{2}$ Column과 DME Column에 대한 Invensys사의 PRO/II with PROVISION을 이용하여 수행 하였으며, 표 8에는 원료와 용매에 대한 조건을 나타내었 다. 본 공정의 목적은 원료 가스 중에서 $\mathrm{CO}_{2}$ 성분을 $\mathrm{CO}_{2}$ 
Column의 상부 증기류로 제거하고 DME Column의 상부 액상 제품으로는 $\mathrm{DME}$ 의 순도를 $99.9 \mathrm{~mol} \%$ 이상으로 얻 는 것과 동시에 메탄올의 함량은 $500 \mathrm{ppm}$ 이하로 수분의 함량을 $100 \mathrm{ppm}$ 이하로 낮추는 것이다. 한편 표 9에는 $\mathrm{CO}_{2}$ 흡수탑과 $\mathrm{CO}_{2}$ Stripper에 대한 설계 조건 및 전사모 사 결과를 나타내었다. 표 9에 의하면 $\mathrm{CO}_{2}$ Column의 운 전압력은 $3,000 \mathrm{kPa}$ 이며 $\mathrm{CO}_{2}$ 의 제거율은 $100 \%$ 이다. 한 편 DME Column의 운전압력은 $800 \mathrm{kPa}$ 이며 탑상부에서 $\mathrm{DME}$ 의 순도는 $99.95 \mathrm{~mole} \%$ 로써 제품 사양 이상의 순도 를 얻었으며, 불순물인 메탄올과 물의 함량도 $500 \mathrm{ppm}$ 이하였다.

[표 8] 원료와 용매의 입력 조건

\begin{tabular}{lr}
\hline \multicolumn{1}{c}{ 성분 } & 원료 \\
\hline 1. $\mathrm{CO}$ & 0.3732 \\
2. $\mathrm{H}_{2} \mathrm{O}$ & 0.2189 \\
3. $\mathrm{CO}_{2}$ & 8.3358 \\
4. $\mathrm{H}_{2}$ & 0.0521 \\
5. $\mathrm{CH}_{3} \mathrm{OH}$ & 2.7609 \\
6. $\mathrm{CH}_{3} \mathrm{OCH}$ & 9.0548 \\
7. $\mathrm{CH}_{4}$ & 0.0480 \\
8. $\mathrm{N}_{2}$ & $6.2998 \mathrm{E}-3$ \\
Flow $(\mathrm{kmol} / \mathrm{hr})$ & 20.85 \\
Temperature $\left({ }^{\circ} \mathrm{C}\right)$ & -49.09 \\
Pressure $(\mathrm{kPa})$ & 3,000 \\
\hline
\end{tabular}

[표 9] $\mathrm{CO}_{2}$ Column과 DME Column에 대한 설계 조 건 및 전산모사 결과

\begin{tabular}{cccc}
\hline 항목 & 단위 & $\begin{array}{c}\mathrm{CO}_{2} \\
\text { Column }\end{array}$ & $\begin{array}{c}\mathrm{DME} \\
\text { Column }\end{array}$ \\
\hline 이론단수 & 단 & 20 & 19 \\
운전압력 & $\mathrm{kPa}$ & 3,000 & 800 \\
응축기 Duty & $10^{6} \mathrm{Kcal} / \mathrm{h}$ & -0.3100 & -0.4013 \\
재배기 Duty & $10^{6} \mathrm{Kcal} / \mathrm{h}$ & 0.5117 & 0.3168 \\
$\mathrm{CO}_{2}$ 제거율 & $\%$ & 100 & - \\
$\mathrm{DME}$ 순도 & $\mathrm{mole} \%$ & - & 99.95 \\
메탄올 함량 & mole ppm & - & 427.7 \\
수분 함량 & mole ppm & - & 71.5 \\
\hline
\end{tabular}

\section{4. 결론}

본 연구에서는 일산 10 톤의 DME를 순도 $99.9 \%$ 이상 으로 얻어내는 분리공정에 대해서 Invensys사의 PRO/II with PROVISION을 활용하여 전산모사를 수행하였으며 다음과 같은 결론을 얻어낼 수 있었다.

1. $\mathrm{DME}$ 분리공정에 가장 적합한 열역학 모델식으로 NRTL 액체 활동도계수 모델식과 Peng-Robinson
상태방정식을 적용하였다. 한편, $\mathrm{CO}, \mathrm{CO}_{2}, \mathrm{H}_{2}, \mathrm{CH}_{4}$ 및 $\mathrm{N}_{2}$ 기체의 물 및 메탄올 용매에 대한 용해도 추 산을 위해서 Henry의 법칙을 사용하였다.

2. 본 연구에서 적용한 열역학 모델식과 비교하기 위 하여 HYSYS에 내장되어 있는 PRSV 모델에 대해 서 자체 데이터베이스를 확인하여 본 결과 $k_{i j}$ 와 $k_{j i}$ 를 동일한 값으로 사용하기 때문에 적합하지 않은 것으로 판명되었다.

\section{사용 기호}

$T$ : 절대온도 $[\mathrm{K}]$

$P$ : 압력 [bar]

$F$ : 목적함수

$T_{c}$ : 임계온도 $[\mathrm{K}]$

$P_{c}:$ 임계압력 [bar]

$R$ : 기체상수 [J/gmole- $\mathrm{K}]$

$a$ : energy parameter $\left[\mathrm{kg} / \mathrm{m}-\mathrm{sec}^{2}\right]$

$b$ : size parameter $\left[\mathrm{m}^{3} / \mathrm{gmole}\right]$

$v$ : 몰부피 $\left[\mathrm{m}^{3} / \mathrm{gmole}\right]$

$\alpha$ : alpha function

$\omega$ : 편심인자

$C_{1}, C_{2}, C_{3}, C_{4}$ : Henry 상수 앞의 계수들

$x_{i}, y_{i}$ : 성분 ' $\mathrm{i}$ '의 액상 및 기상 조성

$y_{j}^{\text {exp }}, y_{j}^{c a l}:$ 'j'번째 실험적인 기상 조성 및 계산된 기상 조성

$T_{j}^{\exp }, T_{j}^{c a l}$ : 'j'번째 실험적인 온도 및 계산된 온도 $[\mathrm{K}]$

$a_{i j}, b_{i j}, \alpha_{i j}$ : NRTL 모델식의 파라메터들

$k_{i j}, k_{j i}$ : Peng-Robinson 상태방정식의 파라메터들

\section{참고문헌}

[1] 조정호, 박종기, 김성태 "PRO/II with PROVISION을 활용한 화학공정의 모사”. 도서출판 아진, 2004.

[2] Renon H., and Prauznitz, J.M., "Local Composition in Thermodynamic Excess Functions for Liquid Mixtures", AIChE J., vol. 14, pp. 135-144, 1968.

[3] Peng, D.Y., and Robinson, D.B., "A New Two-constant Equation of State", Ind. Eng. Chem. Fundam., vol. 15, pp. 1197-1203, 1972.

[4] 조원일, 나영진, 신동근, 임계규, 조정호, “일일 $50 \mathrm{~kg}$ 
$\mathrm{DME}$ 생산을 위한 파일럿 플랜트 분리 정제공정 모 사", 한국가스학회지, 제 10 권, 제 2 호, pp. 22-26, 6월, 2006.

[5] Nelder, J.A., and Mead, R.A., "A Simplex for Function Minimization", vol. 7, pp. 303-313, 1965.

[6] Twu, C.H., D. Bluck, J.R. Cunningham, and J.E. Coon, "A Cubic Equation of State with a New Alpha Function and New Mixing Rule", Fluid Phase Equil., vol.69, pp. 33-50, 1991.

[7] HYSYS Aspen Tefchnology, "HYSYS Quick Start Guide", 2007.

[8] Stryjek, R., Vera, J.H., "An Improved Peng-Robinson Equation of State with New Mixing Rules for Strongly Nonideal Mixtures", The Canadian Journal of Chemical Engineering, vol. 64, No. 2, pp. 334-340, 1986.

[9] PRO/II Application Brief, 2005.

\section{조 정 호(Jungho Cho)}

[정회원]

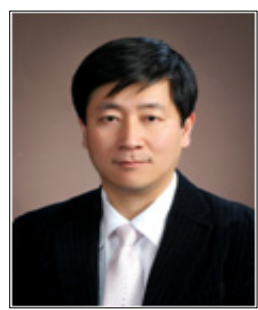

- 1988년 2월 : 한양대학교 공과대 학 화학공학과 (공학사)

- 1991년 8월 : 한국과학기술원 화 학공학과 (공학석사)

- 1998년 2월 : 서울대학교 공과대 학 화학공학과 (공학박사)

- 1991년 1월 1997년 2월 : 대 림산업(주) 공정부 과장

- 1997년 3월 2000년 2월 : 경인여자대학 산업환경공 학부 전임강사

- 2000년 3월 2008년 2월 : 동양대학교 공과대학 생 명화학공학과 조교수

- 2008년 3월 현재 : 공주대학교 화학공학부 부교수

<관심분야>

열역학, 공정 Simulation

\section{김 영 우(Young-Woo Kim)}

[정회원]

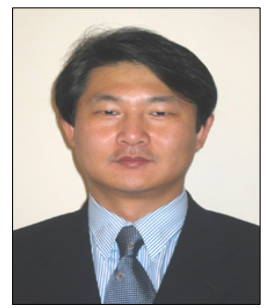

- 2005년 3월 : 미 듀크대학교 공 과대학 토목환경공학과 (공학석사)

- 2006년 1월 : 미 듀크대학교 공 과대학 토목환경공학과 (공학박사)

- 2006년 1월 2006년 12월 : 미 듀크대학교 토목환경공학과 박사후 연구원

- 2007년 1월 2007년 7월 : 미 듀크대학교 공과대학 토목환경 공학과 연구교수

- 2008년 3월 현재 : 호서대학교 자동차공학과 전임강 사

<관심분야>

유체역학, 공정 Simulation 